\title{
CHANGING THE PRACTICE LEARNING LANDSCAPE
}

\section{Dawn A. Morley, Kathy Wilson and Justin McDermott}

\begin{abstract}
$\underline{\text { ABSTRACT }}$
Engagement in real life practice has long been acknowledged as the most effective way to learn a trade or profession and practice learning is consistently highlighted by nursing and midwifery placement students for its impact on both their professional and personal development. The paper examines the current complexities of practice learning that have emerged from educational reform and policy and debates the more recent interest in the development of alternative approaches to practice learning in the UK.
\end{abstract}

\section{INTRODUCTION}

In the late 1990s the UK undertook a national investment in nursing and midwifery education, through the implementation of Project 2000, that made the significant decision to move traditional student training into higher education. Levett-Jones and Lathlean (2008) questioned whether the advances in theory based education have been mirrored in practice education and, despite the considerable investment made in practice learning in other countries, UK nursing has been slow to respond to research highlighting difficulties in practice learning. Dedicated Education Units originating from Australia have, in the same timeframe as the evolution of Project 2000, been adopted in the USA. These clinical areas, focusing on student education (Ranse and Grealish 2007, Moscato et al 2007, Grealish and Ranse 2009, Grealish et al 2010), provide an alternative model of collaborative practice learning for student nurses underpinned by the changing demographics in care. Currently practice learning in the UK is undergoing a significant refocus which questions the mainstays of the practice learning structures that emerged from the Project 2000 reforms. 


\section{THE LEGACY OF PREVIOUS SYSTEMS OF PRACTICE EDUCATION}

Nurse education prior to Project 2000 did not reflect the changing face of health provision or the type of practitioners needed to provide it (RCN 1985; UKCC 1986); "a knowledgeable doer", who used advanced analytical skills in care (UKCC 1986). Melia (1984), in her iconic study on the occupational socialisation of nurses, had observed that the work students were delegated to was far removed from the initial professional decision making made by the nurse in charge. Students were ill prepared for their future roles as they saw a fragmented view of the qualified nurse role where their own professional knowledge was expedient to manageable bureaucratic tasks. Despite the underlying self-regulatory frameworks of Project 2000 that introduced the twin pillars of autonomy and accountability into the new codes of professional conduct (Bradshaw 2001) students' previous conformity to prevailing practice continued to be an identified issue by Holland (1999) and Gray and Smith (1999). The UKCC (1999) attempted to address this by strengthening qualifying students' fitness for practice by advocating an outcome based competency approach to practice learning assessment although this pedagogical approach was criticised for being counter intuitive to producing critical professionals.

\section{IDENTIFICATION OF THE NEED TO CHANGE PRACTICE EDUCATION}

The increased "uncoupling" of university based education and practice led to emotional conflicts with the demise of the nurse teacher's role in clinical practice, and the value of caring in the academic curriculum being devalued (Smith and Allen 2010). This further accentuated the theory-practice split between academia and practice and Allan et al (2011, p. 847) found that students continued "to learn in a disintegrated learning context where opposing values of learning exist". The newly found supernumerary status of students sat 
uncomfortably with clinical staff (Allan et al 2011) and students' work rarely reflected their role as learners (Allan et al 2008).

The influence of a designated "mentor", a qualified nurse, to support students' practice learning (NMC 2004) was recognised as the lynchpin of the educational reforms (Gray and Smith 1999) and pivotal to all aspects of students' professional development in practice (Myall et al 2008). This came with recognised positive and negative effects on student nurse learning (Spouse 2001, Bradbury-Jones et al 2011). Research is, however, incomplete on the role of the mentor in relation to supervision undertaken by health care assistants in student nurses' practice learning (Hasson et al 2013a, 2013b).

Morley (2015) found that, although many students respected the health care assistants to whom they were assigned, a conflicted learning situation arose where students saw alternative supervision by mentors as a superior experience. Work with health care assistants was viewed as lower order work as opposed to learning (Morley 2015). The lack of awareness of the significance of a social model of learning, that could be incorporate all staff into supporting students in practice, meant that Melia's previous identification of the fragmentation of students' learning continued to be replicated. Students gained insufficient exposure to mentors' professional level of decision making that could enable them in their future development as clinical managers. Some mentors are excellent educators and role models while others directed students to work predominantly with unqualified staff and begrudged the time that had to be spent on formal assessment (Morley 2015).

As a by-product of educational reform practice learning in the UK has therefore been caught in the juxtaposition of nurses disputing whether essential care should be given to nontrained staff or whether the recommendations of the poor standards of care highlighted by 
the Francis enquiry (NMC 2013) re asserts a stronger need for nurse education to address the caring aspects of nursing such as dignity and compassion. In response to reports on poor nursing care the RCN commissioned Lord Willis (Willis Commission 2012) to examine what excellence in nurse education may look like. The report recommended the greater integration of theory and practice, the importance of dedicated time for mentorship of students and the stronger emphasis of an enquiry led philosophy in practice.

\section{FUTURE DIRECTION AND POTENTIAL DIFFICULTIES}

Since Willis (2015) there does seem, however, to be a palpable change in the focus on practice learning. Despite complaints from both the Francis enquiry, and the first Willis Commission (Willis 2012), that the nursing profession was slow to respond to their recommendations increased interest in practice learning is evident. The recently published, Educating the Future Nurse, from the Council of Deans of Health (CoDH 2016) highlighted the need for improving practice learning and the quality of practice placements available as part of the overall change needed in pre-registration nursing. Significantly a NMC review is in place of the UK new standards of proficiency for the future graduate registered nurse due out in 2018 (NMC 2016a, 2016b).

Although the transformational nature of the learning that students can experience in practice is firmly recognised, in the UK the post Project 2000 era has been dominated by an emphasis on the product of practice learning rather than the learning process. The best practice learning is often organic and unplanned with both the student and their facilitator having to be agile enough to recognise the situation as learning and to be able to use the incident adeptly so students' practice is changed as a result (Morley 2015). International nursing literature, in particular, emphasises the importance of a clinical learning environment that is supported by all staff. Academic- practice partnerships, that have done 
much to raise the quality of clinical nurse education in Australia (Ranse and Grealish 2007, Moscato et al 2007, Grealish and Ranse 2009, Grealish et al 2010) provides an example of the importance of investing qualified student facilitators into placement. However, this is an expensive and different system where students undertake 880 clinical hours against 2,300 clinical hours in the UK. Although the mentor's assessment role in the UK is one aspect that is recognised by both students and mentors as in great need of reform (Morley 2015) the possible divorcing of learning from assessment (NMC 2016b) could set up a further layer of expensive bureaucracy within a practice learning system that is already overstretched.

For those students who have experienced poor mentorship, and good support from other members of staff, the overemphasis on a sole, named supervisor on placement informs the debate being led by the NMC (2016b). However, the evolution of the mentor in the UK has been unique and this qualified member of nursing staff is unpaid for their mentorship role and has therefore kept the cost of placements relatively low for UK universities. Unusually mentorship in the UK is highly regulated by compulsory training and biannual updates (Bazian 2016).

As the debate stirs on whether all qualified staff should be mentors, and the gatekeeper to students' practice learning on UK placements, it is worth considering the alternatives. Although research suggests that the mentor often feels challenged bridging their clinical role and their teaching role (Morley 2015) they are now an established part of nurse clinical education in the UK. With clear lines of assessment responsibility, and structures of training, mentors are well placed to be an instrument to refocus practice learning. With continuing vulnerabilities between quality care and quality learning it may be premature to consider the dismantlement of established structures of practice learning or a radical alteration of the mentors' role away from clinical assessment. 
The RCN mentorship project (Bazian 2016) presents alternative models and recommendations for enhancing practice learning. The RCN hosted a practice-based education summit recently in conjunction with the $\mathrm{NMC}$ and $\mathrm{CoDH}$ where there was a plea for the profession to move from discussion to action. Alternative clinical supervision models, such as the CLiP (Collaborative learning in practice) project (Lobo et al 2014) derived from Amsterdam, creates a new learning environment of peer support with a designated qualified nurse to supervise. An alternative initiative is the HEE funded STEP (Strengthening Team-based Education in Practice) project led by Middlesex University that works to support placements to achieve their own practice identity through effective use of current resources and all clinical staff.

The current changing landscape in practice learning returns to the pre Project 2000 debate as to how do students learn to be effective qualified nurses. This time around there is a confusing imbalance in nurse education between learning the essentials of care against the continuing evolution of the registered nurses' role away from personal care towards management. There is a lack of recognition and boundaries for the significant and developing role of "helpful others" (Eraut 2007), such as peer students and unqualified staff, in students' official practice learning. Experienced nurse educators who bridged academia and practice are depleted and the mentor's role is now being questioned. There seems to be a need for a brave, over investment in experienced nurse educators in clinical placements where "helpful others" are formally recognised and regulated into a more rounded social model of practice learning.

\section{$\underline{\text { References }}$}


Allan, H., Smith, P., Lorentzon, M. and O’Driscoll, M., 2008. Leadership for Learning, Final Report Centre for Research in Nursing and Midwifery Education Faculty of Health and Medical Sciences, University of Surrey.

Allan, H. T., Smith, P. and O'Driscoll, M., 2011. Experiences of supernumerary status and the hidden curriculum in nursing: a new twist in the theory-practice gap? Journal of Clinical Nursing, 20 (5/6), 847-855.

Bazian, 2016. RCN Mentorship Project 2015, From Today's Support in Practice to Tomorrow's Vision for Excellence, London, RCN

Bradbury- Jones, C., Sambrook, S. and Irvine, F., 2011. Empowerment and being valued: A phenomenological study of nursing students' experience of clinical practice. Nurse Education Today, 31, 368-372.

Bradshaw, A., 2001. The Project 2000 Nurse. The remaking of British General Nursing 19782000. London and Philadelphia: Whurr Publishers

CoDH 2016. Educating the Future Nurse - a paper for discussion. Our initial views on the key outcomes of future registered nurse education, across all four fields.

\section{http://www.councilofdeans.org.uk/2016/08/educating-the-future-nurse-a-paper-for-} discussion/ [accessed 10/09/16]

Eraut, M., 2007. Learning from other people in the workplace. Oxford Review of Education, $33(4), 403-422$.

Gray, M. and Smith, L. N., 1999. The professional socialization of diploma of higher education in nursing students (Project 2000): a longitudinal study. Journal of Advanced Nursing, 29 (3), 639-647. 
Grealish, L., Bail, K., Ranse, K., 2010. 'Investing in the future': residential aged care staff experiences of working with nursing students in a 'community of practice'. Journal of Clinical Nursing, 19 (15-16), 2291-2299.

Grealish, L., Ranse, K., 2009. An exploratory study of first year nursing students' learning in the clinical workplace. Contemporary Nurse, 33 (1), 80-92.

Hasson, F., McKenna, H. P. and Keeney, S., 2013a. Delegating and supervising unregistered professionals: the student nurse experience. Nurse Education Today, 33 (3), 229-235.

Hasson, F., McKenna, H. P. and Keeney, S., 2013b. Perceptions of the unregistered healthcare worker's role in pre-registration student nurses' clinical training. Journal of Advanced Nursing, 69 (7), 1618-1629.

Holland, K., 1999. A journey to becoming: the student nurse in transition. Journal of Advanced Nursing, 29 (1), 229-236.

Levett-Jones, T. and Lathlean, J., 2008. Belongingness: A prerequisite for nursing students' clinical learning. Nurse Education Today, 8, 103-111.

Lobo, C., Arthur, A. and Lattimer, V., 2014. Collaborative Learning in Practice (CLiP) for preregistration nursing students. A background paper for delegates attending the CLiP conference. Collaborative Learning in Practice (CLIP), University of East Anglia. NHS Health Education East of England. Available from: http://eoe.hee.nhs.uk/files/2014/11/CLiP-Paperfinal-version-Sept-14.pdf. Melia, K., 1987. Learning and Working. The Occupational Socialisation of Nurses. London: Tavistock Publications. 
Morley, D.A., 2015 A grounded theory study exploring first year student nurses' learning in practice. (Doctor in Professional Practice), Bournemouth.

Moscato, S. R., Miller, J., Logsdon, K., Weinberg, S., Chorpenning, L., 2007. Dedicated education unit: An innovative clinical partner education model. Nursing Outlook, 55, 31-37. Myall, M., Levett-Jones, T. and Lathlean, J., 2008. Mentorship in contemporary practice: the experiences of nursing students and practice mentors. Journal of Clinical Nursing, 17, 18341842.

NMC, 2004. Standards of Proficiency for Pre Registration Nursing Education. London: NMC.

NMC, 2013. NMC response to the Francis Report. London: NMC.

NMC, 2016a. Programme of change for education Available from

https://www.nmc.org.uk/education/programme-of-change-for-education/ [Accessed 22/09/16]

NMC, 2016b. NMC Education Programme Workshop: Learning and assessment in practice held at RIBA, London in 16 December 2016

Ranse, K. and Grealish, L., 2007. Nursing students' perceptions of learning in the clinical setting of the Dedicated Education Unit. Journal of Advanced Nursing, 58 (2), 171-179 RCN, 1985. The Education of Nurses: A New Dispensation Commission on Nursing Education. RCN: London

Smith, P. and Allan, T. H., 2010. "We should be able to bear our patients in our teaching in some way": Theoretical perspectives on how nurse teachers manage their emotions to negotiate the split between education and caring practice. Nurse Education Today, 30 (3), 218-223. 
Spouse, J., 2001. Bridging theory and practice in the supervisory relationship: a sociocultural perspective. Journal of Advanced Nursing, 33 (4), 512-530.

UKCC, 1986. Project 2000. A new preparation for practice.

UKCC, 1999. Fitness for practice. The UKCC Commission for Nursing and Midwifery Education.

Willis Commission, 2012. Quality with compassion: the future of nursing education. Report of the Willis Commission 2012: Executive summary [online]. Available from:

http://www.williscommission.org.uk [Accessed 23/10/16].

Willis, G., 2015. Raising the Bar. Shape of Caring: A Review of the Future Education and Training of Registered Nurses and Care Assistants. London. 